\title{
Trimethoprim sulfamethoxazole decreased morbidity and mortality in HIV-1 infected patients with tuberculosis
}

Wiktor SZ, Sassan-Morokro M, Grant AD, et al. Efficacy of trimethoprim-sulphamethoxazole prophylaxis to decrease morbidity and mortality in HIV-1-infected patients with tuberculosis in Abidjan, Côte d'Ivoire: a randomised controlled trial. Lancet 1999 May 1;353:1469-75.

QUESTION: In HIV-1 infected African patients being treated for tuberculosis, does the addition of trimethoprim sulfamethoxazole (co-trimoxazole) prophylaxis decrease morbidity and mortality?

\section{Design}

Randomised (allocation concealed*), blinded (clinicians and patients), ${ }^{*}$ placebo controlled trial with median 10.5 month follow up.

\section{Setting}

4 outpatient tuberculosis treatment centres in Abidjan, Côte d'Ivoire.

\section{Patients}

771 patients (mean age $32 \mathrm{y}, 60 \%$ men) who had sputum smears positive for tuberculosis, were HIV-1 positive, or dually reactive for HIV-1 and HIV-2, and met laboratory eligibility criteria (haemoglobin level $\geq 70 \mathrm{~g} / \mathrm{l}$, granulocyte count $>1.1 \times 10^{9} / \mathrm{l}$, platelet count $>100 \times 10^{9} / \mathrm{l}$, serum alanine aminotransferase level $<2.5$ times the upper limit of normal, and serum creatinine concentration $<150 \mathrm{~g} / \mathrm{l})$. Exclusion criteria were positivity for HIV-2, pregnancy, previously treated tuberculosis, allergy to co-trimoxazole, or receipt of co-trimoxazole to prevent recurrent toxoplasmosis. 764 patients (99\%) were included in the analysis.

\section{Intervention}

Patients were allocated to 1 tablet daily of trimethoprim, $160 \mathrm{mg}$, and sulfamethoxazole, $800 \mathrm{mg}(\mathrm{n}=386)$, or placebo $(\mathrm{n}=385)$. All patients received tuberculosis medication for 6 months.

\section{Main outcome measures}

Death and $\geq 1$ hospitalisation.

\section{Main results}

$85 \%$ of patients in the co-trimoxazole group took $\geq 75 \%$ of their medication. During follow up, fewer patients who received co-trimoxazole died $(\mathrm{p}<0.001)$, or were hospitalised $(p=0.02)$ than patients who received placebo (table). The rates of death and hospitalisation increased with decreasing CD4 cell count. The groups did not differ for adverse events.

\section{Conclusion}

In HIV-1 infected African patients treated for tuberculosis, the addition of trimethoprim sulfamethoxazole prophylaxis decreased mortality and need for hospitalisation.

*See glossary.

Trimethoprim sulfamethoxazole (co-trimoxazole) v placebo for HIV-1 infected patients with tuberculosist

\begin{tabular}{lclll}
$\begin{array}{l}\text { Outcomes at } \\
\text { median } 10.5 \text { mo }\end{array}$ & Co-trimoxazole & Placebo & RRR (95\% CI) & NNT (CI) \\
\hline Death & $13.3 \%$ & $22.6 \%$ & $41 \%(19$ to 57$)$ & 11 (7 to 26$)$ \\
\hline$\geq 1$ hospitalisation & $7.6 \%$ & $12.4 \%$ & $39 \%(5.6$ to 61$)$ & 21 (11 to 172$)$ \\
\hline
\end{tabular}

†Abbreviations defined in glossary; RRR, NNT, and $\mathrm{Cl}$ calculated from data in article.

1 Hovette P, Camara P. Respiratory manifestations of salmonelloses in AIDS patients. Int J Tuberc Lung Dis 1999;3:743-4.

2 Greenberg AE, Lucas S, Tossou O, et al. Autopsy-proven causes of death in HIV-infected patients treated for tuberculosis in Abidjan, Côte d'Ivoire. AIDS 1995;9:1251-4.

Sources of funding: Centers for Disease Control and Prevention; Rockefeller Foundation; Roche African Research Foundation.

For correspondence Dr $S$ Wiktor, Projet RETRO-CI, O1 BP 1712,01 Abidjan, Côte d'Foire. Fax +225 404 6394268 